\title{
Minor Axis Cross-sectional Diameter at End Ventricular Systole
}

National Cancer Institute

\section{Source}

National Cancer Institute. Minor Axis Cross-sectional Diameter at End Ventricular Systole. NCI Thesaurus. Code C127576.

The cross sectional diameter a cardiovascular structure measured in the minor axis at end ventricular systole. 